DIW BERLIN

Discussion

Papers
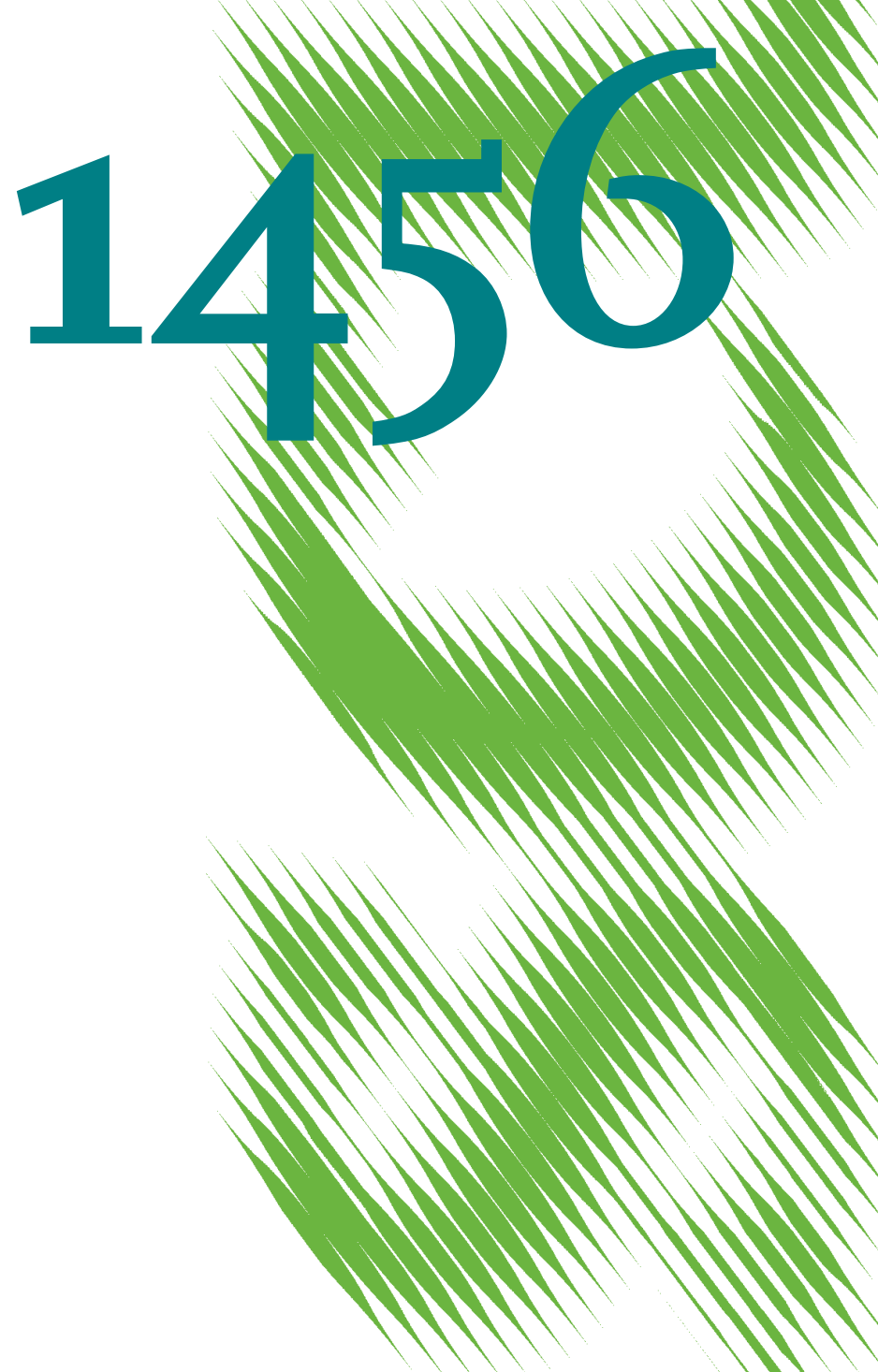

Power Market Design beyond 2020: Time to Revisit Key Elements? 
Opinions expressed in this paper are those of the author(s) and do not necessarily reflect views of the institute.

IMPRESSUM

(C) DIW Berlin, 2015

DIW Berlin

German Institute for Economic Research

Mohrenstr. 58

10117 Berlin

Tel. +49 (30) $89789-0$

Fax +49 (30) $89789-200$

http://www.diw.de

ISSN electronic edition 1619-4535

Papers can be downloaded free of charge from the DIW Berlin website:

http://www.diw.de/discussionpapers

Discussion Papers of DIW Berlin are indexed in RePEc and SSRN:

http://ideas.repec.org/s/diw/diwwpp.html

http://www.ssrn.com/link/DIW-Berlin-German-Inst-Econ-Res.html 


\section{Power Market Design beyond 2020: Time to Revisit Key Elements?}

\section{Karsten Neuhoff, Sophia Ruester and Sebastian Schwenen ${ }^{1}$}

We revisit key elements of European power market design with respect to both short-term operation and longer-term investment and re-investment choices. For short-term markets, the European policy debate focuses on the definition of common interfaces, like for example gate closure time frames. We argue that this is, however, insufficient if the market design is to accommodate for the different needs of renewable and conventional generation assets and different flexibility options. The market design needs to ensure that resources are pooled over larger geographic areas, that the full flexibility of different assets can be realized with complex bids and that scarce network resources are efficiently used. For investment and re-investment choices we argue that different technology groups, i.e. maturing wind and solar PV versus fossil fuel based generation may warrant a different treatment - reflecting the different level of publicly accessible information, requirements for grid infrastructure, types of strategic choices relevant for the sector and share of capital cost in overall generation costs. We discuss opportunities for such a differentiated treatment and implications thereof.

Keywords: Power market design, regulation, investment framework

JEL: L11, L94, G32

\footnotetext{
${ }^{1}$ German Institute for Economic Research (DIW Berlin), Department of Climate Policy, Mohrenstrasse 58, 10117 Berlin. Corresponding author: kneuhoff@diw.de. The authors gratefully acknowledge financial support from the German Federal Ministry for Economic Affairs and Energy (grant no. 03MAP274, EUREEM).
} 


\section{Introduction}

Electricity markets were liberalized to create incentives for efficient operation and investment choices by private actors while reducing government intervention. ${ }^{2}$ The separation between public and private institutions through privatization, and a shift from cost-based to incentive regulation also resulted in more independence of public policy makers from utility interests and allowed for the formulation of climate policy objectives and instruments to guide the transition to a low-carbon electricity sector. The standard approach to liberalization involved the creation of competitive wholesale markets, regulated transmission and distribution networks, and competitive retail markets.

This paper explores two developments to this paradigm at the level of wholesale markets. First, with respect to the operation of wholesale markets, an increasing attention is dedicated to the institutional setting of the market place, both with respect to the role of power exchanges as trading platform and with respect to the role of system operation that is fulfilled in Europe by transmission system operators (TSOs). We will therefore discuss implications for TSOs' operational procedures. Second, with respect to investments, traditionally a horizontal separation between investments under regulated (transmission, distribution) and competitive (wholesale and retail) frameworks was envisaged and prominent. The recent experience points to a potential further differentiation of investments in the wholesale domain. Investment, re-investment and closure choices for thermal plants and different flexibility elements remain prominently based on revenues in the wholesale market, while investments in capital-intensive assets like wind or solar PV are typically pursued with additional long-term contractual arrangements with regulatory backing to hedge revenue streams for investors and energy costs for consumers. We will therefore discuss potential motivations for such a separation and the implications for a market and regulatory design that supports the full portfolio of technologies.

With respect to an efficient operation of the power system, the so called EU Target Model provided the vision that is to be gradually translated into a common institutional framework based on a process of framework guidelines provided by a European regulatory agency (ACER, the Agency for the Cooperation of Energy Regulators), and being translated into a binding set of regulation (via so called Network Codes) by the Association of European Transmission System Operators (ENTSO-E) with the approval of the European Commission.

So far, much of the Target Model discussion was concerned with the definition and alignment of market protocols for the different interfaces between TSOs and other market participants. Progress on implementation was largest in systems with abandoned flexibility from dispatchable generation and largely unconstrained transmission capacity. In contrast, countries like Spain, Italy, Poland or Ireland with scarce transmission or limited generation flexibility have not been able to implement the vision of the Target Model. Their TSOs would struggle to balance the system or resolve transmission constraints in the short period left after gate closure. Instead, these countries have developed different solutions based on centralized auction platforms or coordination mechanisms for intraday adjustments that can reflect ramping- and reserve requirements, or transmission constraints. This suggests that the Target Model - if it continues to focus on the definition of interfaces and (gate

\footnotetext{
${ }^{2}$ For an in-depth discussion of privatization and liberalization of the European energy sector and its wider historical context see Pollitt (2012).
} 
closure) time frames - might struggle to obtain acceptance across EU countries, and where it is implemented could cause an increasing divergence of internal TSO operational approaches.

A first motivation for the further integration of system operation between EU Member States is the pooling of resources over larger geographic areas, being necessary to guarantee system security in an efficient manner. Generation in one country can help to satisfy demand in neighboring countries, depending on power generation portfolios and available cross-border transmission capacities. Moreover, critical situations of very high demand, but low (and maybe even inadequate) levels of supply, will occur less frequently when considering a larger geographic area. First, fluctuations in RES generation differ among regions. Second, fluctuations in demand do so as well. Peak demand may occur during different moments in time due to cultural differences and differing time zones. Finally, also varying demand response potential has to be taken into account. Thus, the quantity of resources needed to meet a given security standard decreases with an increasing size of the market. A question that still remains to be discussed is how to align the regional scope of pooling resources with the level and governance of local responsibility for system security.

A second motivation for progress on the operational paradigm is the increasing diversity of generation and demand-side technologies that need to be integrated in an efficiently operated system. Thus, the bidding process has to reflect both the pressure to enhance the temporal granularity of products, and generation assets' technical capabilities. This is of particular relevance where access for new technologies and increased levels of competition depend on the entrance of additional market participants and thus no longer allow the reliance on vertically integrated utilities that historically balanced their own demand and supply schedule and today continue to pursue internal balancing through private balancing groups in several EU Member States. With increasing shares of intermittent RES, and therefore larger intraday adjustment volumes, pooling across all actors and therefore the coordination function of the market before gate closure gains in importance. If, for instance, a generation unit needs to increase production to match growing demand during the morning period, or to react to declining solar input in an afternoon hour, a typical energy contract for one hour cannot meet the low (resp. high) output volume at the beginning (end) of the period. Thus, there is some pressure to enhance the temporal granularity of traded products allowing to match supply and demand on 15 or 5 minute intervals.

At the same time, coal, nuclear and most combined cycle gas turbines require several hours to startup and can only be ramped gradually to full output. These technologies will struggle to use 15 minute type products to make more than marginal adjustments to their production profile. ${ }^{3}$ The perceived conflict between increasing temporal granularity, while at the same time respecting technical plant capacity in the bidding structure could be resolved with a complex bid format. Market participants here submit bids reflecting not only marginal generation costs (or value of load for demand-side resources), but also inter-temporal constraints. The auction clearance then can produce a feasible generation schedule that can be balanced on short-term (e.g. 5 minute) intervals. Complex bid formats used today in EU power markets differ among Member States, and usually are mere block bids defined to match historic system or technology requirements. Therefore, further development and convergence will be essential.

\footnotetext{
${ }^{3}$ This is less of a concern for utilities with a portfolio of generation units across which they can optimize, or where generators can use bilateral trading opportunities to re-trade generation schedules that are infeasible.
} 
A third motivation for progress on the operational paradigm is that flow-based transmission allocation and smaller pricing zones can enhance efficiency in the use of transmission capacity. In the past, the European transmission grid exhibited only very limited constraints and markets were separated into - typically national - pricing zones. Cross-border transmission capacity was initially grandfathered to incumbents, then allocated on first-come-first-serve basis and eventually auctioned as physical transmission capacity to market participants. The separate clearance of transmission and energy markets, however, reduced the efficiency of transmission use. Therefore, the majority of EU day-ahead markets are now coupled with implicit auctions that jointly allocate transmission and clear energy markets. In a next step, flow-based market coupling is currently being implemented at dayahead stage, and transmission capacity is allocated to transactions where it offers the highest value. TSOs, however, struggle to provide robust information on the transmission capacity that can be made available for flow-based market coupling, as this information has to be provided before the day-ahead market clears and, therefore, at a time when the generation pattern within zones is still uncertain. This has triggered additional interest in revisiting the geographical definition of pricing zones. Smaller pricing zones offer two benefits: First, they reduce the likelihood of transmission constraints occurring within a zone and the need for redispatch. Second, they reduce the uncertainty about generation and load patterns within a zone, and thus allow for more accurate grid modelling and making more transmission capacity available to the market.

Thus, a set of further developments to the operation of the power system seems warranted and needs to be advanced to ensure that all generation and demand-side technologies can provide their full value to the power system.

A second development of the paradigm relates to the framework that guides investments, reinvestments and closure decisions for different generation and demand side technologies. One key point of discussion in recent years was the role attributed to renewable energy sources in the liberalized power market. While it had become accepted that renewable support mechanisms are necessary and have been successful in facilitating learning by doing and market introduction, perspectives still vary widely on how in a longer-term - e.g. post-2020 - the regulatory framework and market design can support efficient operation and investment choices for all generation technologies.

To facilitate this discussion it seems suitable to focus initially on two technology groups with fundamentally different characteristics: First, capital costs linked to the initial investment constitute for around $80 \%$ of total power generation costs of wind and solar PV, while their share for conventional mid-merit and base-load generation assets is typically in the order of $30 \%$. Second, in the case of RES, volume and location of new investments remain the most important decision parameters. In contrast, for conventional generators, the prominent questions relate to retrofit or closure/mothballing decisions, and suitable fuel contracting. Finally, also the capacity of governments to take a stronger part in strategic decisions varies. For RES, information about costs is largely in the public domain, and can be solicited through competitive market arrangements like auctions or responsive feed-in mechanisms. In contrast, for conventional generation, regulators face challenges of asymmetric information if they attempt to involve in re-investment or closure decisions. The different requirements for an effective investment framework for these generation technologies and correspondingly also for different flexibility options like storage and demand side response - are reflected in different needs for policy developments. 
For conventional generation technologies as well as many flexibility options with moderate up-front investment costs forward contracting is central. Current surplus generation capacity in several European countries motivates companies to consider the mothballing or decommissioning of generation units. Despite the expectation that gas-fired power stations will add significant value to a future low-carbon power system, often gas-fired power stations are short-listed for closure. The option value associated with the potential revenues of a plant in future years motivates companies to retain assets online even if annual fixed costs are not recovered in the short-term. Where the balance sheet of companies is tight, or where major re-investments are required, however, the focus might shift to the actual cost of maintaining an unprofitable unit operating. The challenge for maintaining supply adequacy therefore is likely to be a challenge of coordinating sticky (re)investment and closure decisions across multiple actors. The coordination challenge is further complicated through strategic incentives which might distort utilities' decisions and the credibility of information made available. ${ }^{4}$

Historically, investors were willing to undertake investment in liberalized electricity markets based on the limited length of forward contracting and a retail customer basis. Can this remain the basis for the limited volume of remaining investment requirements and larger shares of re-investment needs in conventional assets? Also, will price signals, especially from option contracts, facilitate investments in demand response capability? This could largely be a question of the demand for forward contracts. Mid-term contracting allows to hedge against high price volatility. However, demand for forward contracting differs across countries due to institutional settings, consumer preferences and regulatory design. Industrial clients will chose their contracting volumes reflecting an overall risk management strategy, the pricing process in their product market and impacts of counterparty risks of contracts. Losses incurred by industrial clients with contract cover exceeding their production volume during the economic crisis reduced contracting interests. Retail customers were historically seen as a stable demand basis against which long-term investment could be financed, but a revisited regulatory emphasis on retail competition might challenge this assumption. This raises overall questions on the future development of mid-term contracting structure and volumes - and the impact of policy design.

In contrast, for intermittent renewable technologies like wind and solar the central design requirement is linked to a policy framework that facilitates efficient financing, as their economics are dominated by up-front investment costs. Therefore, access to capital to finance the investments, and the associated cost of capital) are essential for the execution and competitive operation of renewable projects. Financing costs are determined by the risk associated with the investment: First, the secure net-revenue determines the share of debt that can be used to finance a project and to reduce financing costs; and second, complexity of the regulatory framework and financial structure may increase transaction costs and reduce the level of competition because fewer actors will have the capacity to engage.

This paper discusses these different dimensions in more detail, starting with the requirements formulated for short-term power markets in Section 2, followed by a discussion on why a differentiated investment framework might be warranted for different generation and flexibility

\footnotetext{
${ }^{4}$ Utilities might benefit, if excess decommissioning results in higher market prices for remaining generation assets. Utilities might aim to delay the announcement of plant closures so as to encourage competitors to close plants. In less competitive markets utilities might attempt to prematurely announce plant closures where this could offer opportunities to negotiate additional support from regulators.
} 
options in Section 3. We specifically discuss the investment framework at the example of conventional generation technologies in Section 4 and for wind and solar PV in Section 5, before briefly concluding in Section 6.

\section{Requirements for short-term power markets with large shares of intermittent RES}

The EU Target Model ${ }^{5}$ focusses on the definition of interfaces among actors in the electricity sector and (gate closure) time frames. In what follows we discuss why this approach might struggle to obtain acceptance across EU countries, or could even cause divergence of TSOs' operational approaches. We explore system needs for the integration of increasing shares of intermittent generation as well as the further development of the Target Model to address these needs.

\subsection{Target Model could cause increasing divergence of operational approaches}

\subsubsection{Today's focus of Target Model on definition of interfaces between market participants}

The EU Target Model clearly defines the responsibilities of transmission system operators. These include system operation, the management of network constraints and the operation of markets for balancing and system services (EC, 2009). ${ }^{6}$ Other actors in the power system to whom TSOs are interlinked are (i) generating and consuming agents (or aggregators thereof), (ii) market operators (i.e. power exchanges) and (iii) third system operators (both transmission and distribution):

Generation/load: With the Third Package ${ }^{7}$, activities in the competitive sectors of generation and supply are separated from grid operation ("effective unbundling"). ${ }^{8}$ TSOs, though, contract generation (and increasingly also load) resources to balance the system and manage network constraints. Moreover, in some countries TSOs have been assigned new tasks, like selling RES power contracted on feed-in tariffs, or acquiring electricity storage capacity.

\footnotetext{
${ }^{5}$ The Network Codes currently drafted by ENTSO-E treat day-ahead and intraday capacity allocation and congestion management, forward capacity allocation, different aspects of system operation (operational security, load frequency control, etc.), cross-border balancing, and technical rules on grid connection. For an overview on background, areas of policy intervention and timeline see http://www.acer.europa.eu/Electricity/FG_and_network_codes/Pages/Background-and-timeline.aspx

${ }^{6}$ Directive 2009/72/EC: A TSO is "responsible for operating, ensuring the maintenance of and, if necessary, developing the transmission system in a given area and, where applicable, its interconnections with other systems, and for ensuring the long-term ability of the system to meet reasonable demands for the transmission of electricity." For the detailed TSO tasks see Art. 12.

${ }^{7}$ The Third Package, adopted in 2009, consists - for the electricity sector - of the Directive concerning common rules for the internal market in electricity (2009/72/EC) and Regulations on conditions for access to the network for cross-border exchange of electricity (714/2009) and on the establishment of the Agency for the Cooperation of Energy Regulators (713/2009). The aim is to create a single, functioning EU energy market with high standards of service and security of supply.

${ }^{8}$ Three possible models of TSO unbundling: (1) ownership unbundling, (2) an independent system operator (i.e. the transmission system remains with vertically integrated company, but system operation is performed by the ISO), or (3) an independent transmission operator (i.e. asset ownership and system operation stay within the vertically integrated company, but the ITO is supposed to be independent from the integrated company).
} 
New challenges for the interface TSO - generation/load: With the increasing penetration of intermittent generation and the resulting increasing volatility of residual load, the time frame at which the volume of required reserve and response capacity is determined, and the efficient selection of resources to serve these requirements, needs to be aligned with the substantially improving forecasts as real-time is approached, so as to utilize the physical capabilities of the system to react.

Market operators: In the EU, power exchanges serve as market operators and provide platforms to trade intraday, day-ahead and forward contracts. With the Target Model, power exchanges have also been allocated the responsibility to allocate transmission capacity between countries/pricing zones through explicit and increasingly also implicit auctioning procedures. They receive information on available transmission capacities from TSOs.

New challenges for the interface TSO - market operators: The generation pattern varies with local weather conditions that determine wind and solar production, and with forecast errors decreasing substantially the closer one comes to real-time. Changes to flow patterns impact the transmission capacity that can be made available for commercial transfers. Therefore, the one-directional process of TSOs providing information on available transfer capacity to market operators (being the result of capacity calculation processes carried out by the TSOs) needs to become more interactive or even fully integrated with the process of capacity allocation.

Distribution system operators ${ }^{9}$ : Historically, distribution networks had been dimensioned so as to facilitate at all times access of all load and distribution-connected generation to the transmission grid ('fit-and-forget approach'), thus effectively passing through all generation and load directly to the transmission network.

New challenges for the vertical TSO - DSO interfaces: With increasing shares of generation connected to lower-voltage grids and the increasing role of demand responsiveness, the distribution system needs to be operated more actively to anticipate and respond to transmission constraints on the distribution grid, using also local energy resources connected to it. Such activity will have to be well coordinated with the upstream TSO.

Adjacent TSOs: The transmission grid can allow for the pooling of flexibility resources over a broader geographic area. The physics of meshed transmission grids also imply that any scheduled transmission flow is distributed across all transmission paths it really uses. The interactions across the entire transmission system require close coordination of TSO activities.

New challenges for the horizontal TSO - TSO interfaces: With increasing shares of intermittent RES, generation patterns and thus flow patterns can vary more widely and with shorter-term notice. Coordination among TSOs therefore needs to become more interactive, and needs to happen within day-ahead and intraday timeframes, including real-time.

The Target Model to date has primarily focused on defining and improving the interfaces between the above actors (Figure 1). Thus, it reflects the demand of market participants for the early definition of products and opportunities for bilateral trading until close to real-time (focus on gate closure time). The TSO is tasked to calculate transmission capacity for exchange with other pricing

\footnotetext{
${ }^{9}$ Article 29 of Directive 2009/72/EC allows for 'combined transmission and distribution system operators', however, in most Member States, TSOs and DSOs are separate entities, with a very heterogeneous DSO landscape across the EU.
} 
zones for power exchanges, to estimate and exchange flow patterns with neighboring TSOs, and to contract balancing reserves and system services from generation and load resources. Until gate closure about an hour before real-time, the TSO is expected to accept nominations from generation and load profiles from market participants. In principle, it is expected that the TSO only gets active after gate closure to balance the system using contracted balancing reserve and to resolve violations of internal transmission constraints using redispatch.

Figure 1: Interfaces as defined by the EU Target Model

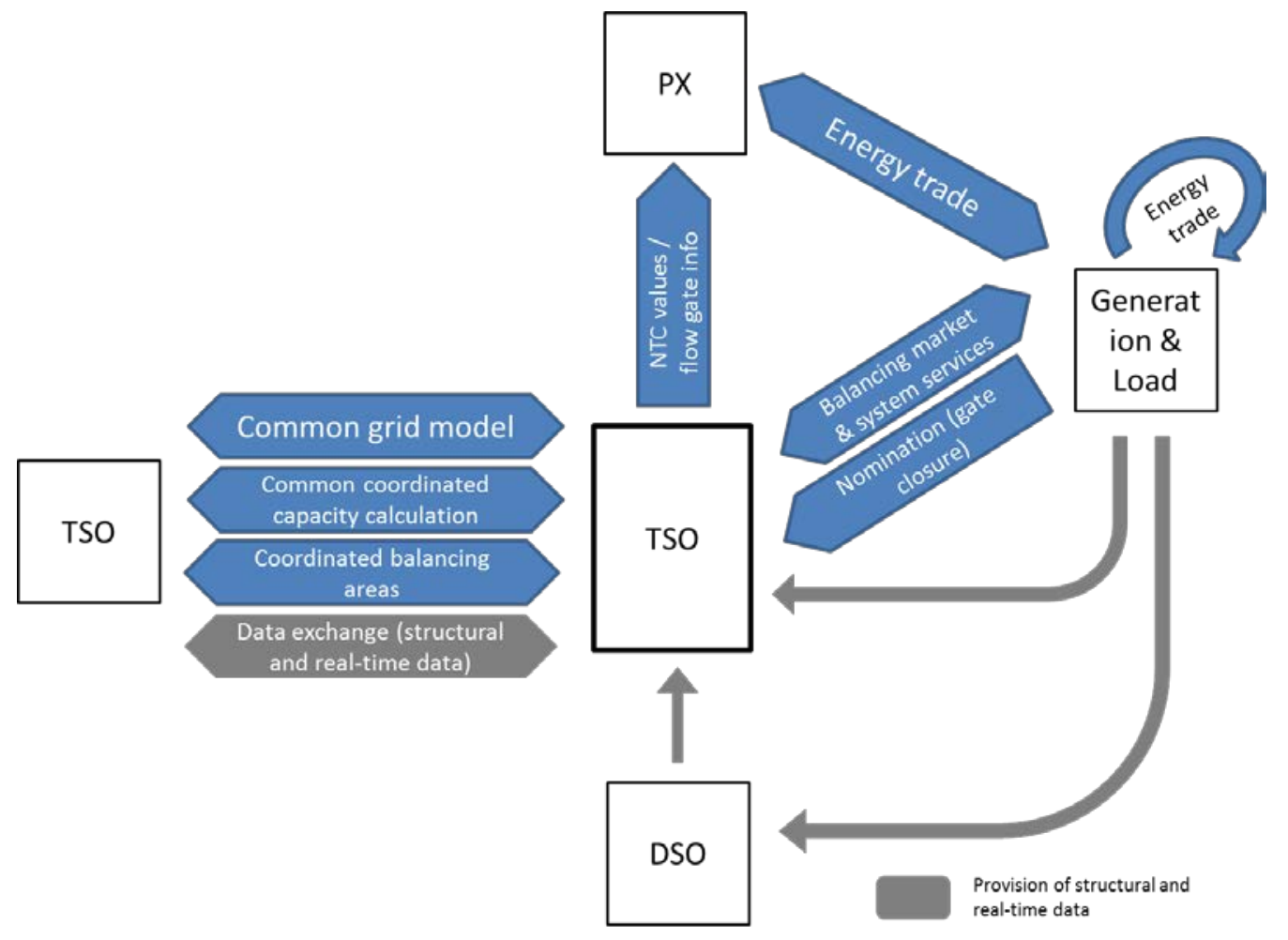

Source: Authors' own depiction

Progress on implementing the Target Model was largest in Central Western European countries with abandoned flexibility from dispatchable generation and largely unconstrained internal transmission capacity. In contrast, countries like Spain, Italy, Poland or Ireland with scarce transmission or limited generation flexibility have not been able to facilitate a pure zonal market model. Their TSOs would struggle to balance the system and resolve transmission constraints in the short period left after gate closure, for example because internal transmission constraints and therefore redispatch needs are more severe, or because less flexible generation capacity is available to provide the suitable response (decision to start up thermal units is needed 6 to 8 hours ahead). Instead, these countries have developed different types of solutions based on centralized auction platforms or coordination mechanisms for intraday adjustments that can reflect transmission constraints, ramping constraints and reserve requirements. ${ }^{10}$

\footnotetext{
${ }^{10}$ For an extensive discussion of the Spanish intraday market design see Chaves-Ávila and Fernandes (2015). For an overview on the Polish way of combining nodal and zonal approaches see Sikorski (2011).
} 
This suggests that the Target Model - if it continues to focus on the definition of interfaces and (gate closure) time frames - might (i) struggle to obtain acceptance across EU countries and even where countries would implement it, (ii) could cause increasing divergence of operational approaches as TSOs aim to align the Target Model requirements with their national generation mix and grid situation.

\subsubsection{Improving vertical TSO-DSO coordination}

With increasing shares of renewable energy and flexible load connected to the distribution systems, distribution systems are challenged by new features, i.e. increased volatility of net demand and peak demand fluctuations and even reverse flows from the distribution to the transmission level in times of local generation exceeding local demand. The increasing decentralization of the productionconsumption loop and flexibility of consumers challenges the top-down control logic of traditional power supply (Schleiche-Tappeser, 2012; Leprich, et al., 2008). Local grids will therefore have to be operated such as to avoid violation of voltage and thermal constraints on both distribution and transmission lines. ICT companies have discovered new fields of activity and drive the ongoing transformation through the creation of variety, in terms of technology, business models and value chains (see e.g. Erlinghagen and Markard, 2012).

Moreover, behaviors in local grids will more and more influence the efficiency of system functioning. The management of load or generation for purposes of the secure operation of distribution networks will typically also impact the flows to or from the transmission network and, therefore, will have to be coordinated with the TSO. Likewise, if load and generation on the distribution network is used to provide flexibility at the transmission level, this will impact distribution network flows, too. For an indepth discussion on the need to therefore rethink the current regulation of electricity DSOs see also Ruester et al. (2014).

The regulatory focus on the interface from TSOs to the market, as exemplified in the Network Codes, leaves much room for different options on how DSOs can be integrated into system operation and to what degree coordination among DSOs and TSOs needs to be guided. It remains to be discussed if we may need a clearer definition of the vertical interface between DSOs and the respective TSO. Moreover, it remains to be discussed if a different overall approach to TSO operation might simplify the interface with DSOs.

\subsubsection{Improving horizontal TSO-TSO coordination}

A functioning internal electricity market should allow for unlocking flexibility resources across national borders and pricing zones. This calls for closer TSO-TSO coordination and convergence of operational procedures. Two processes are enhancing the level of coordination among TSOs.

First, the Network Codes establish relatively concrete provisions on data exchange requirements, including both structural data on grid topology and technical characteristics of grid users, forecast data (e.g. aggregate sum by primary energy source of injection and withdrawal in every node of the transmission system for the different timeframes), as well as some real-time data (such as actual system state, active and reactive power situation). Moreover, harmonized rules on cross-border capacity allocation, congestion management and balancing aim to support the efficient use of existing transmission capacities. 
Second, different platforms for TSO cooperation have been created to the already existing UC(P)TE association set up back in the 1950s to coordinate the operation and development of the interconnected power systems of Continental Europe. ETSO (launched in 1999) aimed to study and develop common market principles in order to enhance network operation and system security and to facilitate the internal market. Seven Regional Initiatives ${ }^{11}$ (created in 2006 and bringing together TSOs plus other stakeholders) aim to accelerate the integration of Europe's national electricity markets. Since 2009, ENTSO-E has become an official European body representing all European TSOs and working amongst others on the development of the Network Codes. Moreover, cooperation happens via individual voluntary agreements, one of which the TSC Initiative ${ }^{12}$ ("TSO Security Cooperation"), where 12 TSOs active in 10 Member States established a permanent TSO Security Panel and implemented a shared IT platform for exchanging data and assessing mutual security needs.

These inter-TSO activities have led to increasing inter-TSO operational cooperation. However, it seems nowadays that it cannot be moved forward as TSOs reach limitations in their cooperation coming from differing national market designs across Europe. It seems that further cooperation in this area can be ensured only if market design and regulatory framework are more harmonized Europe-wide.

\subsection{Operational needs for power systems with large shares of intermittent RES}

\subsubsection{Suitable bidding format}

Historically, vertically integrated utilities largely balanced their own demand and supply schedule and used trading opportunities to fill generation gaps or use arbitrage opportunities from different plant efficiencies or fuel costs. With increasing shares of intermittent RES in third party ownership, the coordination function of the market before gate closure increases in importance. This has resulted in pressure to both enhance the temporal granularity of products and to mirror the plant capabilities in the bidding process:

Temporal granularity: If a generation plant needs to increase production to match growing demand during the morning period, or to react to declining solar production in an afternoon hour, then a typical energy contract for one hour cannot meet the low output volume at the beginning and high output volume at the end of the period. Hence, some market participants and TSOs were interested to enhance the temporal granularity of products in order to improve the match of supply and demand on 15 or 5 minute intervals.

Respect plant capacity: Coal, nuclear and most combined cycle gas turbines require several hours to start-up and can only be ramped gradually to full output (VDE, 2012). These technologies therefore will struggle with energy markets with market clearing processes for individual hours. This is less of a concern for utilities with a portfolio of generators across which they can optimize, or where generators can use bilateral trading opportunities to re-trade generation schedules that are infeasible.

\footnotetext{
${ }^{11}$ I.e. the Baltic, Central-Eastern, Central-Southern, Central-Western, Northern, South-Western and FR-UK-IR regions. See also: http://www.ceer.eu/portal/page/portal/EER_HOME/EER_ACTIVITIES/EER_INITIATIVES/ERI

${ }^{12}$ http://www.tscnet.eu/
} 
Hence, different bid formats have been developed that link the output of several hours or include bid components for start-up and ramping to allow effective participation of less flexible generation assets. Figure 2 illustrates recent developments in European electricity markets. The traditional hourly bid format has in some countries, like Germany, been disaggregated at intraday stage into intervals of 15 minutes, thus facilitating a closer match of supply and demand within an hour with the drawback of limiting the participation of plants that might not be able to respond so quickly and reducing compatibility with neighboring countries. Many countries allow for block bids that can bundle the production profile of several hours to facilitate participation of less flexible plants, but possibly increasing the ramps (and thus imbalances) at the margins of the blocks. The different formats of block bids used in the Central-Western European (CWE) market region have posed one of the biggest challenges for the implementation of market coupling, as the market coupling algorithm had to be developed so as to accommodate for all different formats.

Figure 2: Recent developments in bidding format

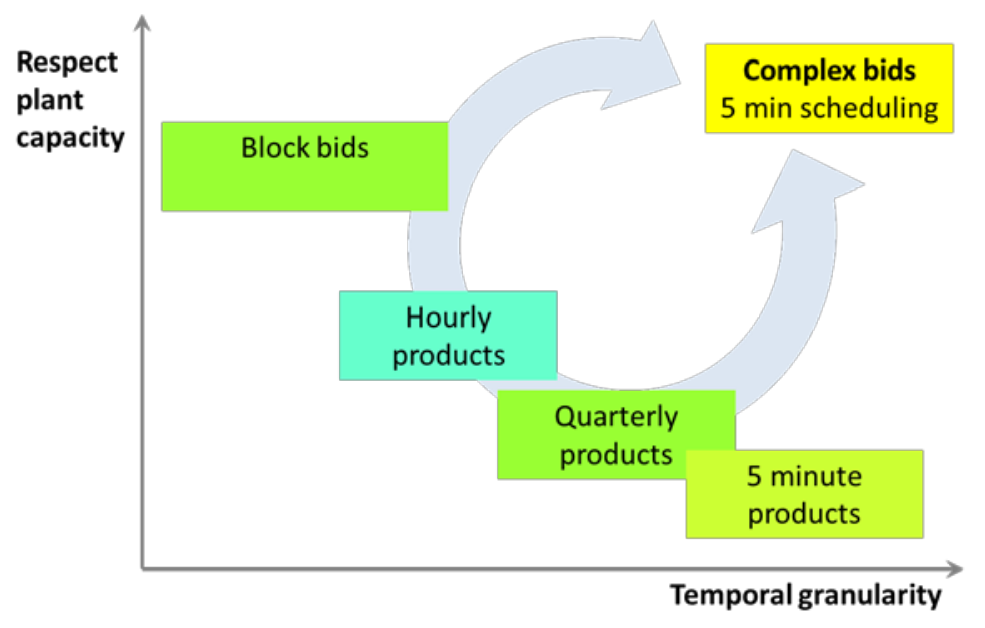

The perceived conflict between the objectives of increasing temporal granularity on the one hand, while at the same time respecting for plant capacity in the bidding structure could be resolved with a complex bid format. Market participants here can submit bids reflecting not only marginal generation costs (or value of load for demand), but also inter-temporal constraints including minimum output levels, non-divisible blocks, feasible ramping rates as well as start-up costs. This ensures that the auction clearance produces a feasible generation schedule that can be balanced on short-term (e.g. 5 minutes) intervals. A detailed bidding mechanism is used for example in the Polish balancing market. Generators here can submit constraints related to individual units, including minimum output levels, feasible ramping rates and start-up costs, which are taken into account in the TSO scheduling process.

\subsubsection{Procurement of reserve and response}

TSOs contract different reserve and response products to balance the system in real-time. Reserves have historically been defined according to the response speed and capability of conventional generation assets to sustain additional production. With new generation technologies and demand options, TSOs might adjust their definition of reserve products so as to allow for their participation, too. With increasing shares of intermittent RES on the system, the maximum volume of reserve 
required for a certain hour depends, for example, on the share of wind generation operating at a wind speed close to $25 \mathrm{~m} / \mathrm{s}$ and thus close to potential shut-off. Increasingly, TSOs are adjusting the volume of reserve contracted to the specific needs. An additional reason motivates shorter-term contracting of reserves. The production of intermittent RES and therefore also the operation of conventional generation assets that "fill the gaps" cannot be predicted on the time frames (weeks and month) on which reserve had been traditionally contracted. Moreover, the increasing interaction between energy and reserves markets indicates the efficiency improvements that can flow from a joint market clearing of the coupled energy and reserve products.

Figure 3: Energy versus reserve markets

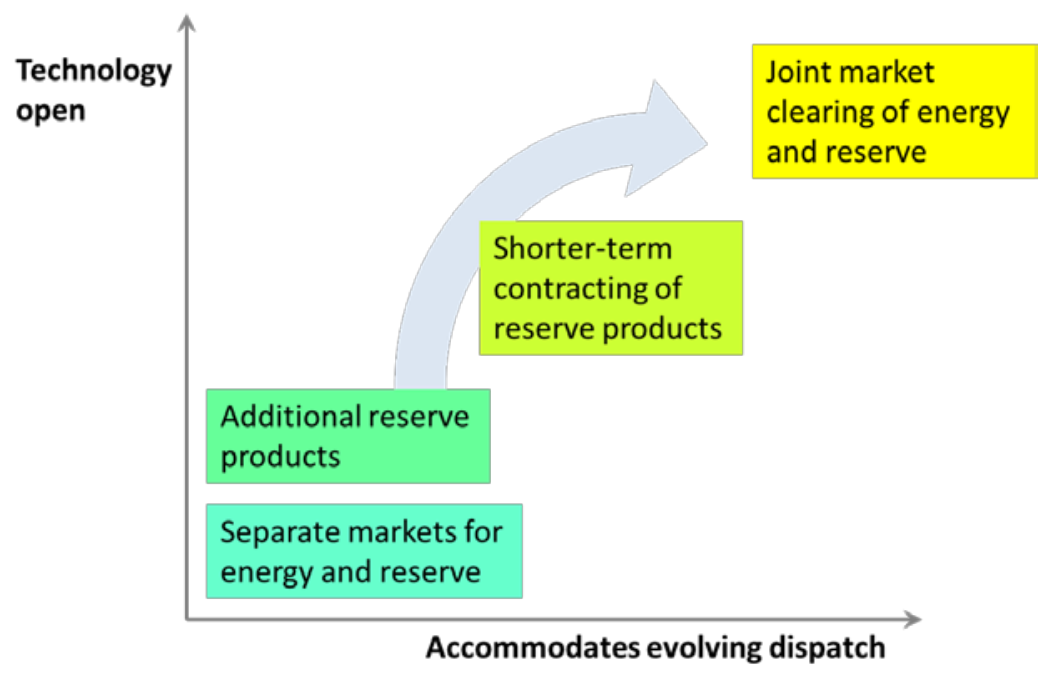

The Target Model has envisaged so far the definition of common reserve products and procurement rules. Reserves can be shared by TSOs based on algorithms for transfer of balancing capacity and activation optimization and were efficient transmission capacity can be reserved using physical transmission rights to facilitate such reserve sharing subject to transmission constraints. This pooling of reserve offers efficiency gains, but raises the question whether the standardization has been implemented based on a suitable procedure. Otherwise the standardization might risk further progress towards openness for new technologies and shorter term adjustment of reserve requirements and contracting, let alone joint optimization across energy and reserve.

\subsubsection{The role of balancing groups}

Several European countries have implemented the concept of balancing groups. Deviations by individual plants can be compensated by other plants within the same group. However, as TSOs have no visibility of reserve and response provision within balancing groups they continue to acquire at all times reserve and response to avoid the risk of potential imbalances. Thus, synergies of the systemwide pooling effect are lost with the balancing group.

Balancing groups that are in imbalance are exposed to explicit imbalance penalties in some countries, and face implicit penalties in all countries. Implicit penalties arise because the concept of balancing groups encourages balancing within groups and thus limits the liquidity of the balancing (real-time) market, thus increasing the spreads and costs of imbalance. The concept also ensures that large 
market participants can leverage the benefits of their generation portfolio: The larger the portfolio, the more imbalances within the portfolio will be canceled by the pooling effect or can be balanced or compensated by operational decisions. Thus, imbalance volumes and costs as share of total sales revenue are smaller for large firms providing some competitive advantage. The structure of imbalance tariffs can partially attempt to compensate for this effect. Ultimately, small firms either have to contract with large firms or with other aggregators to reduce imbalances - creating market opportunities for incumbents and traders.

Figure 4: Balancing groups

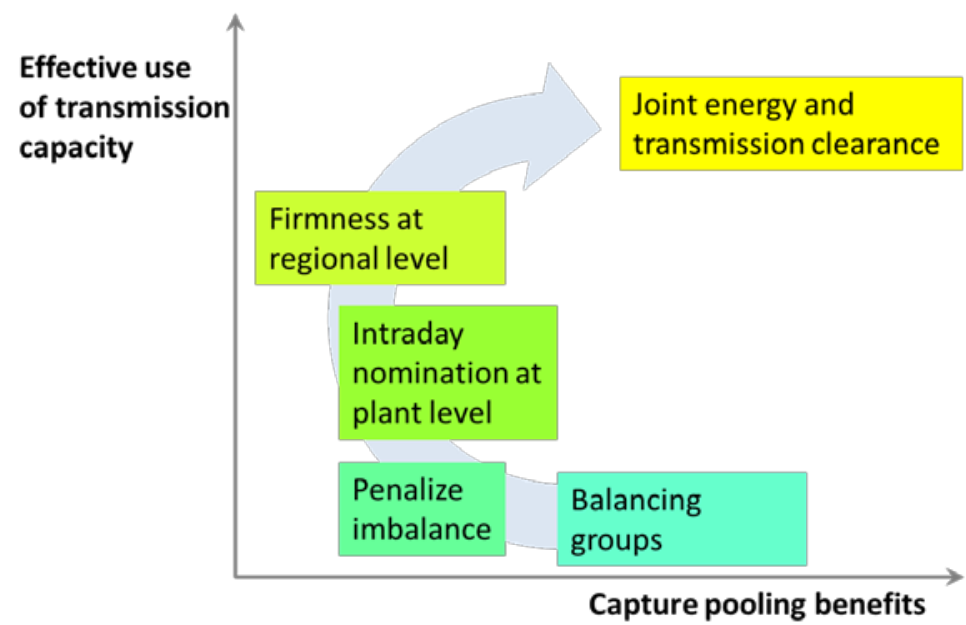

The philosophy of balancing groups assumes unlimited transmission capacity within a pricing zone so as to allow for any changes in production or demand to be balanced at any physical location in the zone. In practice, transmission capacity within each pricing zone is limited, and hence the German regulator, for instance, has recently introduced the requirement that market participants nominate their generation and load schedules for each location at day-ahead stage and inform the TSO about any intraday changes. This is a first step towards redesigning the concept of balancing groups. An even more far-reaching solution has been implemented in Belgium, where a color coding system is used to coordinate re-nominations at intraday stage in response to internal transmission congestion.

If transmission capacity is limited, then pooling within balancing groups is no longer possible in the entire pricing zone, but only in smaller geographical areas. This increases the value of sharing flexibility beyond the balancing group with other generation and load in the smaller geographical area, and thus the value of an effective short-term and real-time market. The next section will discuss how effective transmission use can only be combined with the pooling effect, if transmission and energy markets are jointly cleared.

\subsubsection{Effective use of transmission capacity}

The European transmission grid exhibited only very limited constraints within countries as long as the generation mix had not changed. As a result it was possible to abstract from any transmission constraints in so called pricing zones that typically covered one country. Trade between these pricing zones required access to transmission capacity that was initially grandfathered to incumbents, then 
allocated on first-come-first-serve basis and eventually auctioned as physical transmission capacity to market participants.

The separate clearance of transmission and energy markets, however, reduced the effectiveness of transmission use. Therefore, the majority of EU day-ahead markets are coupled with implicit auctions that jointly allocate transmission and clear energy markets. This was a first step of making more use of the flexibility of the transmission grid for market participants.

In a next step, flow-based market coupling is being currently implemented at day-ahead stage. This approach creates additional flexibility for the utilization of transmission capacity - to be allocated to transactions between countries/pricing zones where it offers the highest value. TSOs, however, struggle to provide robust information on the transmission capacity that can be made available for flow-based market coupling, as they have to provide this information before the day-ahead market clears and, therefore, at a time when the generation pattern within zones is still uncertain.

Figure 5: Spatial dimension

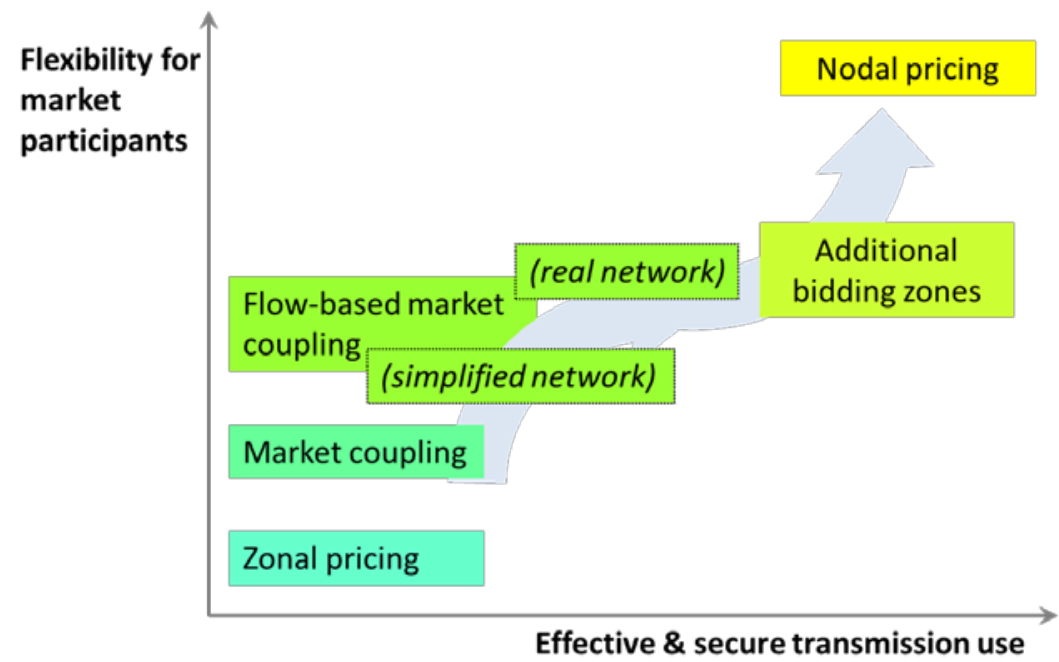

This has triggered additional interest revisiting the question of the geographical definition of pricing zones (see e.g. Breuer and Moser, 2014; Burstedde, 2012). Smaller pricing zones offer two benefits: First, they reduce the likelihood of transmission constraints occurring within a zone (the cause of loop flows) and thus the need for reserving transmission capacity between zones (to accommodate these loop flows) and the need for redispatch. Second, they reduce the uncertainty about generation and load patterns within a zone, and thus allow for more accurate grid modelling (generation shift keys become less volatile) and offering more transmission capacity to the market. Thus, transmission capacity can be used more effectively and the system can be operated more securely. Without a detailed understanding of the load and generation pattern, the TSO otherwise has to provide for very uncertain outcomes of flow patterns, resulting typically in a combination of higher security margins and higher risks of exceeding the security margins.

It is often incorrectly argued that with smaller pricing zones also the liquidity is declining. Just the opposite, as long as markets are coupled through implicit auctions, at any time at which transmission capacity is not fully utilized, the market clearing price remains responsive to demand and supply in the pricing zones. With flow-based transmission allocation, even at times of transmission constraints 
the allocation of transmission capacity to the most valuable use implies that markets remain coupled and mutually responsive. In consequence, the liquidity is maximized, however, restricted only to the feasible transaction. For the same reasons, smaller pricing zones do not lead to increasing the issue of market power if applied both to energy and reserve products.

Creating additional (smaller) pricing zones to allow for more effective and secure transmission implies that also trade between zones (relative to trade within a zone) will increase. Such trade requires transmission contracts to hedge for price risk. While currently transmission contracts are only issued for one year in advance, there are good reasons to expand this period. Hence, it might be considered to directly shift to a high-level zonal resolution, e.g. nodal pricing. Experience in the US has shown that liquidity of forward markets matches the most liquid European market (Germany) and transmission risk can be effectively hedged with transmission contracts that can be implemented for long periods. ${ }^{13}$

\subsubsection{Gate Closure}

With intermittency, transmission system operators face higher uncertainties on flow patterns that result from day-ahead market clearing. To calculate implied flow patterns, to coordinate with neighboring TSOs, and where necessary initiate adjustments to unit commitment, firm nominations for generation- and load schedules would be required already at intraday stage and sufficiently ahead of real-time. Without sufficient time before delivery for conducting all needed calculations and cross-border coordination, cost-efficient solutions for (re)-dispatch are not granted.

Moving gate closure further away from real-time would give TSOs the possibility to conduct all required processes. However, the needs of TSOs have to be in line with the demand of market participants to balance their positions. To do so, after market participants' firm nominations at an earlier gate closure time (potentially several hours before real-time), an auction platform administered by the TSO could allow market participants to place bids in order to respond to new information on their generation and demand profile and to offer flexibility to other market participants. This way, the auction clearing algorithm can also incorporate network constraints and allow for bids reflecting technical constraints of market participants as discussed above.

If transmission constraints within zones are not considered in day-ahead and intraday markets prior to the firm nomination, then the system-wide optimization including these constraints in the first auction after the nomination can result in significant adjustments towards a more efficient outcome. The changes in bidding formats from bilateral to TSO administered markets (applying complex bids for example), however, can also create gaming opportunities between markets that clear according to different principles. Both effects are already a concern in the current arrangements in particular associated with gaming opportunities linked to re-dispatch choices like e.g. the inc-dec game, see also Neuhoff et al. (2011). In this context, it remains open whether continuous trading that is based on a first-come-first-serve base can be employed within complex bidding mechanism that tend to rely on standardized intervals for market clearing.

\footnotetext{
${ }^{13}$ In the US context, trading hubs - reflecting average prices of a region - attract most liquidity and serve as reference point for transmission contracts both to hubs in other regions and to individual nodes within the region. For a comparison of electricity wholesale markets in the US and Europe see also Imran and Kockar (2014).
} 
However, empirically standardized auctions lead to higher liquidity and also from this perspective are the preferred design element, especially with intraday adjustments becoming more and more important. Experience from current intraday markets shows that markets with standardized auctions are among the highest in intraday liquidity throughout the EU with 52 TWh being traded in the Spanish intraday market and 15.8 TWh in the Italian market in 2012 (ACER/CEER, 2012).

\subsection{Conclusions and implications for the Target Model}

Much of the Target Model discussion so far was concerned with the definition and alignment of market protocols for the different interfaces, rather than placing the core of TSO operation itself in the center of the debate. It lacks a shared perception, let alone guidance, on the operational paradigm to be used by TSOs.

In this vein, the Target Model (with its respective Network Codes) sets rules on some standardized exchange of structural-, forecast- and real-time data and on the state of the system. It requires the establishment of a common grid model and a coordinated cross-border capacity calculation. However, it leaves open details on the TSOs' underlying individual grid models, on how to exactly calculate e.g. generation shift keys (estimation of generation pattern, etc.), or on how to determine security margins. The Target Model also gives some guidance on reserve and response products, but not on how to calculate the necessary volumes. For the intraday timeframe, there are requirements to make capacity available to the market, but it is not defined how to exactly calculate this capacity. For balancing after gate closure, there are rules regarding gate closure times, and system operators shall agree, at least with all system operators of the same Capacity Calculation Region, on redispatching and/or countertrading arrangements. But there are no formulations on how to do the respective re-dispatch.

This leaves TSO operation as a kind of black box - (a) risking secure system operation as without an agreed TSO operational approach, no reference point exists to determine e.g. how much time a TSO will need to balance the system. This can risk setting gate closure too close to real-time, leaving insufficient time for balancing; (b) risking efficient cooperation as without clarity on the definition of generation shift keys and security margins, TSOs are likely to determine these with different methodologies and thus either underestimating potential deviation between projected and realized flow patterns jeopardizing system security, or overestimating these deviations, resulting in an inefficient transmission use; and (c) risking harmonized operation as without such international coordination is difficult to integrate with regional security systems and will therefore have to be pursued on manual or heuristic basis. This will be increasingly inaccurate and risky as the share of intermittent RES increases and previously unknown flow patterns emerge. Furthermore, joint security management is difficult to realize as approach for integrated calculation (e.g. based on exchange of shadow prices for critical interfaces) and requires common time protocols for internal calculations.

The analysis above has demonstrated that for multiple reasons we are likely to move towards a central auction platform (at regional level) at intraday and real-time and possibly already day-ahead stage. The clearing algorithm for the auction can combine both energy and reserve requirements and can jointly consider transmission constraints when clearing the energy bids. The price (day-ahead or real-time) emerging from this platform can then also serve as reference for bilateral financial contracts. 
It remains open though whether common market protocols suffice to ensure a secure and efficient operation of the European power system in the longer-term. Despite a common Target Model, operational approaches of TSOs might diverge rather than converge. We may wonder if for the post2014 period not internal TSO operation approaches themselves need to get more attention in further refinements of market protocols and in provision of regulatory guidance for TSOs in order to avoid increasing divergence in processes, and foster a deeper cooperation among system operators.

What are, therefore, the implications for the next steps of the Target Model? Do aligned market protocols and a clearer definition of interfaces between system operators and market participants suffice? Or do we instead need a clearer definition and potentially a degree of harmonization of core operational approaches of TSOs as basis for the design and implementation of interfaces to the market and other system operators? In this case, would it be necessary to ensure that long-term robust solutions will be considered during the further refinement of the Target Model? Any lock-in effects when adapting the market design need to be avoided (see also Neuhoff and Newbery, 2005). We then might wonder if we can do all the steps described above as individual steps, and whether we need to go through all these individual steps. There are not only complementarities but also negative inter-linkages - the concept of balancing groups with firm nominations on the balancing group level for instance is not compatible with the move to significantly smaller zones and the move towards efficient intraday allocation of transmission capacity (with the last based on detailed flow calculations which in turn would need to rely on firm capacity on the plant level). On the other hand, certain adaptations might be better done jointly, e.g. the same step at the same time across countries, or several steps as one package within one country.

\section{Two types of generation need to be differentiated}

For maturing renewable energy technologies, such as wind and solar PV, it is widely discussed among academia and policy makers whether it is economically beneficial, from a governance perspective possible, and legally appropriate to continue a differentiated treatment from conventional assets. This ultimately boils down to the question whether conventional and renewable generation technologies constitute different goods in terms of different production profiles, etc. As a first approach towards discussing these points, the following table explores differences between these two technology groups.

Capital costs linked to initial investment costs constitute for around $80 \%$ of total power generation costs of wind and solar PV, while their share for conventional mid-merit and base-load fossil fuel power generation assets was typically in the order of 30\% (Schroeder et al., 2013), and is of declining relevance for total cost in a European power market with limited new investment needs in conventional assets. Therefore, a policy framework that aims to minimize costs to final consumers would need to focus on minimizing such capital costs in the case of renewables, while other operational incentives and fuel supply strategies might be equally or more important in the case of fossil fuel based generation plants.

This is reflected in the main strategic choices faced for the different generation technologies. In the case of solar and wind power, volume and location of new investments remain the most important aspects to be considered. Effective investment choices increasingly need to be pursued with a system-wide perspective on the suitable generation mix and require strong coordination with grid expansion. Deployment has to date been successful where supported and guided by government 
deployment targets (RE-Shaping, 2011). In contrast, for fossil fuel plants across Europe the prominent questions relate to re-investment/retrofit enhancing lifetime, plant efficiency and flexibility parameters, to closure/mothballing decisions, and to suitable fuel contracting with only very limited new investments in gas- and coal-fired power generation expected in the foreseeable future.

Table 1: Differences among wind and solar PV as compared to conventional technologies

\begin{tabular}{|l|l|l|}
\hline & Wind and solar PV & Fossil fuel based generation \\
\hline Capital costs & $\sim 80 \%$ & $\sim 30 \%$ \\
\hline Main strategic choices & $\begin{array}{l}\text { New investment decision } \\
\text { Location and dimensioning }\end{array}$ & $\begin{array}{l}\text { (Re-)investment and retrofit decision } \\
\text { Closure } \\
\text { Fuel contracting }\end{array}$ \\
\hline $\begin{array}{l}\text { Capacity for government } \\
\text { to decide }\end{array}$ & $\begin{array}{l}\text { High } \\
\text { (homogenous technology, competition for } \\
\text { entry) }\end{array}$ & $\begin{array}{l}\text { Low } \\
\text { (inhomogeneous assets, large incumbent } \\
\text { players, information asymmetries) }\end{array}$ \\
\hline Other aspects & $\begin{array}{l}\text { Trajectory required for } \\
-\quad \begin{array}{l}\text { Grid investment } \\
\text { Supply chain / planning }\end{array}\end{array}$ & $\begin{array}{l}\text { Government choices politically } \\
\text { contentious }\end{array}$ \\
\hline Strategic choices & Policy-driven deployment & $\begin{array}{l}\text { Private-sector determined (financed } \\
\text { on balance sheet) }\end{array}$ \\
\hline
\end{tabular}

Also the capacity of governments to take a stronger part in such strategic decisions varies. In the case of renewable technologies, information about costs is largely in the public domain, and can be solicited through competitive market arrangements like auctions or responsive feed-in mechanisms. In contrast, information about re-investment needs of individual conventional plants is in private hands, and regulators face challenges of asymmetric information if they attempt to involve in related re-investment or closure decisions. Hence, in the case of renewables, there is both a need and a capacity for public agencies to take a stronger role in strategic investment choices, while in the case of fossil generation assets there is less capacity for public actors to get involved in such choices.

In addition, it needs to be considered, that for successful wind and solar deployment, network expansions are necessary. They are difficult to design by transmission and distribution system operators, to approve by regulators, and to accept by the public if not linked to politically determined RES deployment targets. Such targets are also very valuable for the supply chains, so as to allow manufacturers and grid companies to invest in innovation and manufacturing capacity to meet future deployment targets at least cost. In contrast, closure choices of fossil power stations are often politically contentious and might be better pursued if implemented by private actors looking at the economics of the specific unit rather than based on the influence different stakeholders can exert in political decision processes.

In summary, the comparison of wind and solar PV on the one hand with fossil generation technologies on the other points to economic and governance aspects that could motivate a differentiated treatment. 


\section{Mid-term: (Re-)investment framework for conventional assets and flexibility}

The current surplus generation capacity in several European countries ${ }^{14}$ has resulted in low margins and flat price profiles, motivating companies to mothball (time for re-operation 6-9 month) or decommission plants and providing little incentive for demand side options and interfaces to other sectors. This raises the question on the appropriate policy response to maintaining generation adequacy with a generation technology mix that is compatible with security of supply and environmental and flexibility requirements of the evolving power system. For conventional assets this - for the next decade - will largely be a question about (re-)investment and closure choices, but may also involve investment in some additional plants. In what follows, we discuss the role of forward contracting, market design to ensure full remuneration of the value provided to the systems, unlocking various flexibility options and coordination and insurance during a transition.

\subsection{Forward contracting stabilizes revenue streams and guides (re-)investment}

Past investments in liberalized power markets illustrate the value of mid-term forward contracting (i.e. $>1$ year ahead). In the past, investors in generation assets were willing to undertake investments based on forward contracting and a vertically integrated retail customer basis with strong preferences for contracting. ${ }^{15}$ Forward contracts are equally important for demand side response and for enhancing flexibility through interfaces with industry, heat and transportation, as contracts can translate uncertain revenues from occasional periods of peaking prices into more stable revenue streams. The debate of (re-)investment frameworks for conventional assets and incentives for flexibility options is, however, usually focused on a contrast between an energy-only market built around spot market revenues and long-term commitments with capacity mechanisms. ${ }^{16}$

Incentives to sign forward contracts differ by types of agents. The demand side is interested in signing contracts to stabilize fuel costs and to avoid volatility in household (public) budgets or firm profitability, as well as to secure (re-)investment choices in energy-intensive industries. ${ }^{17}$ Generation is interested in and relies upon signing mid-term contracts to hedge price volatility. Forward contracting volumes, yet, differ across the EU. ${ }^{18}$ The preference of customers for contracting might even be constrained by regulation. For instance, in Spain, last resort tariffs are set on a quarterly basis and are seen as a benchmark for retail prices. These frequent changes then disincentivize both demand and generation to lock into mid-term contracts. Furthermore, national regulatory adjustments (e.g. tax on generation) can be passed on to spot prices but would not be reflected expost in forward contracts.

\footnotetext{
${ }^{14}$ See also ENTSO-E (2014).

${ }^{15}$ For an analysis of forward contracting and vertical integration as a mean to hedge risks in electricity markets see Aïd et al. (2011).

${ }^{16}$ See e.g. Cramton et al. (2013). For a discussion on supply security in the German context and proposed capacity mechanisms see Neuhoff et al. (2013).

${ }^{17}$ For a discussion on how forward contracting increases firm value as incentives to underinvest are reduced see Bessembinder (1991).

${ }^{18}$ See Eurelectric (2010).
} 
In addition, retail competition is usually based on provisions allowing retail consumers to switch suppliers on short notice. As a result, retail companies face inherent uncertainties about their customer base, and will thus not be in a position to sign many contracts for a duration beyond the contract duration with their customers. Allowing for short-notice changes of suppliers could thus reduce the length and liquidity of mid-term contracts at the wholesale level. ${ }^{19}$

Forward contracts can also reduce the risk of regulatory intervention in response to high spot prices during scarcity periods. If consumers are directly - or through their supplier - covered by mid-term contracts, then the total electricity bill will not increase during periods of high spot prices and thus pressure on regulators to intervene is limited. This effect will be of increasing importance, if power prices are seen as a means of coordinating the power system response to periods of low renewable generation that could result in high prices over several days (rather than current peak prices focused on individual hours only). Hedging against the spot price, though, does not eliminate the economic incentive of the spot price. For instance, reducing consumption below the contracted volume can provide savings that will be valued at the spot price, and can thus create situations in which consumers can profit from the flexibility they can offer to the market.

Finally, forward contracts contribute to a more predictable market outcome by reducing three uncertainty factors. First, utilities benefit, if excess decommissioning results in higher power prices for their generation assets. Production that is already contracted will not benefit reducing any strategic incentives. Second, utilities have incentives to delay announcements of plant closures so as to encourage competitors to close plants. Forward contracting can provide more credible information on envisaged production capacity. Third, utilities might attempt to prematurely announce plant closures where this could offer opportunities to negotiate additional support from regulators. Forward contracting provides price signals and longer visibility and can reduce the need for regulators to micro-manage decisions in an environment of highly asymmetric information.

\subsection{Fully remunerating value provided to the system}

For multiple reasons the current market design does not yet fully remunerate assets for the value they provide to the system. This needs to be corrected to provide appropriate (re-)investment signals.

Regulators and system operators like to avoid disconnecting loads. Thus, in situations with scarce generation capacity, operational or transmission reserve margins may be reduced so as to meet demand. Any reduction of operational reserve margins, however, comes at a cost for system security that should be priced to the market. Therefore, several US power markets have now implemented "operational reserve demand curves" so as to reflect the full system costs in short-term prices (Hogan, 2012). As a result, power prices are now more frequently in the range of hundreds of dollars per MWh, a price level easily acceptable for consumers and attractive as contribution for generation to recover fixed costs.

In response to the generation scarcity situation in Belgium linked to sudden unavailability of several nuclear power stations in the fall of 2014, TSOs increased the commercial transmission capacity made available to the market for imports into Belgium above previously calculated levels. For

\footnotetext{
${ }^{19}$ Also Neuhoff and de Vries (2004) observe insufficient levels of long-term contracts and relate this to the risk of supplier-switching.
} 
generation companies that anticipate recovering fixed costs during periods of scarcity, such ad-hoc interventions to moderate scarcity are of concern, as reduced scarcity also lowers power prices. If such capacity is available without increasing operational risks, then it should be offered to the market at all times. If the provision of such additional capacity comes at an increased operational risk, then this additional risk should be priced to the market. This would likely require that congestion management systems more closely reflect the physical reality of individual constrained interfaces and constraining load and generation by reducing the size of pricing zones.

Large pricing zones create a further risk for full remuneration of the value provided by generation assets. In the German-Austrian pricing zone, during high wind periods the initial market clearing results in too much Northern and too little Southern power generation. Subsequent additional generation is scheduled in Southern Germany using a cost-based re-dispatch algorithm that also uses generation assets retained in a reserve specifically to avoid generation scarcity in Southern Germany ("net reserve"). However, this higher marginal cost is not reflected in the market clearing price and thus does not impact remuneration for generation assets in Southern Germany. As a result, the economic viability of assets is reduced below the value they provide to the system, and some assets need to be retained on the system with additional regulatory measures.

\subsection{Unlocking flexibility options}

As the share of intermittent renewable energy is increasing, so is the value of flexibility (see e.g. Schill and Kemfert, 2011; Schill, 2014). While the initial focus is on short-term flexibility to accommodate large gradients of renewable power generation, an increasing value is anticipated for flexibility that can accommodate for variations between day and night or even for spells of low production and high demand during a cold winter week.

The portfolio of flexibility options, which includes demand and supply side, as well as different types of energy storage, is an important element in an effective power market. While any power market can provide sufficient remuneration to provide revenues that would cover investment costs, with limited flexibility and increasing shares of fluctuating renewables this may involve high levels of price volatility and uncertainty that might be difficult to hedge. Increasing the flexibility of the system can reduce the volatility und uncertainty and thus is a central element towards facilitating investments in energy-only markets.

Across Europe, multiple studies have been pursued to assess the scale of flexibility that can be brought to the market (EWI, 2012; Ecofys, 2014; Bertsch et al., 2015). There is broad agreement that only very limited shares of flexibility have been realized to date. On the demand side, larger-scale and industrial consumers offer substantial remaining and economic potentials. Further potentials are e.g. linked to interactions with the heating/cooling sector and e-mobility. However, to date power markets may not provide access to or not fully remunerate the value of demand side flexibility, for example because of bid formats in reserve and response tailored for the capabilities of generation assets (see e.g. Ruester et al., 2013). Thus, as discussed in Section 2, further developments, in particular on intraday- and real-time markets as much as on forward contracting arrangements, can remove barriers for flexibility options.

Many demand side options involve new (control) technologies, operational procedures and business models, and thus take some time to develop at scale. While for some short-term flexibility options the economics are already favorable in todays' market situation, the provision of flexibility for longer 
periods (e.g. hours) is with current surplus generation capacity not viable. This raises the question whether there will be sufficient time for implementing the different flexibility options at scale once they are viable in a market without generation surplus so as to allow for their contribution towards generation adequacy? If the technology and market development of flexibility options requires several years, not least to provide confidence to regulators responsible for generation adequacy, then it might be suitable to start catalyzing the development and early deployment of a portfolio of flexibility options before scarcity emerges.

\subsection{Coordination of the transition}

The transition towards a low-carbon power system comprises multiple uncertainties on technology and market developments like shale gas, PV prices, energy storage, demand response, and the penetration of electric vehicles. It is also clear that several of these developments will be influenced by government policy, thus contributing a further uncertainty factor. As a result and as already discussed above, many argue in favor of capacity mechanisms in order to allocate responsibility on the volume of generation capacity to be contracted with governments and reduce the risk for private investors. An alternative approach towards achieving this objective is the further development of a shared perspective of the transition pathway of a sector. A common understanding reflected in targets, for example on the share of renewable generation, also creates visibility for the need and value of conventional generation and can thus guide (re-)investment and closure decisions.

\subsection{The role of capacity mechanisms}

The specifics of capacity mechanisms range from comprehensive centralized capacity auctions, as envisaged and planned in the UK, to comprehensive decentral capacity markets as in France (Süßenbach et al., 2011; Neuhoff et al., 2013). Alternatively, a strategic reserve is existing or being installed in many European countries such as Sweden, Finland or Poland. Capacity mechanisms thus can either remunerate all generation and flexibility that contribute to generation adequacy (comprehensive capacity mechanism) or can contract generation assets that will only be used if markets no longer clear or if the price exceeds a strike price (strategic reserve).

The different mechanisms reflect different situations and priorities across EU Member States. The UK focuses on long-term guarantees to investors in new generation assets, while the French design aims to realize shorter-term opportunities of demand side flexibility to moderate demand peaks. The German network reserve retains generation assets on the system that would otherwise not recover their annual fixed costs as the single German pricing zone does not reflect the higher value of generation assets in the South. In all cases, the capacity mechanism reflects the high importance attributed to generation adequacy and limited confidence of policy makers that current power market design provides the necessary incentives to secure such adequacy.

While differing national drivers may motivate national-specific mechanisms, they may impose costs at the European scale (Glachant and Ruester, 2014; EU, 2012). They can distort the efficient operation of the European market by allocating capacity costs to foreign load (example Ireland-UK or Russia-Finland) and also through prioritization of load covered by the capacity mechanism over load in other regions at times of load shedding. Uncoordinated national mechanisms are also likely to result in too much generation capacity at European scale and thus higher costs for consumers (Ruester and Schwenen, 2014). This can both increase complexity of the European power market, 
and result in more fragmented responses to system emergencies. Any capacity mechanism should therefore be compatible with the EU internal market rules (ACER, 2013).

Multiple design choices exist on aspects like qualification requirements, price formation, contract duration and penalty for non-delivery. An integrated European market would - in principle - require a common approach for most of them to facilitate international participation in capacity mechanisms.

For comprehensive capacity mechanisms the first question relates to contract duration. Revenues will only be of relevance for generation investments, if they involve a long-term commitment. Whereas the roadmap for conventional generation assets is still widely debated in most European countries, the UK Climate Change Committee has clearly defined, and Parliament agreed, a decarbonization trajectory for the power sector. Without such an agreed roadmap, a policy debate about the design specification of a capacity mechanism like contract duration, years prior to contract start, penalties, size of lots and various pre-qualification requirements would de facto decide on generation mix albeit in a non-transparent manner. However, the alternative of short-term oriented comprehensive capacity mechanisms will have only very limited impact for investment choices, as market participants face high uncertainties about the future development of such a mechanism. Short-term capacity mechanisms might create incentives for short-term oriented choices, e.g. on demand flexibility.

Second, any type of comprehensive capacity mechanism will transfer some of the value previously attributed to electric energy provided in a specific moment to a capacity value. Uncertainty about the ability to participate in capacity mechanisms of neighboring systems and the value that can be captured reduce the incentives to pursue investments in storage or other flexibility options to serve the European market.

The discussion on a UK-Norwegian interconnector points to a further uncertainty. With scarce interconnection capacity between both countries, the capacity value should be attributed to the interconnector. As interconnection capacity increases, it should move to generation assets. If capacity values are however attributed on an ad-hoc manner, past investments are unlikely to benefit, and future investments are uncertain about remuneration levels to be expected.

Finally, comprehensive capacity mechanisms may negatively impact forward markets. If the value of energy provided is divided into energy and capacity components, the energy contract will depend and vary with the last. Furthermore, if designs like reliability options make generation companies liable for a charge of the level at which the spot price exceeds a strike price of the reliability option, then the same generator can no longer sign simple forward contracts as this would create a double liability at times of high spot prices. Foreign providers of reliability options face a similar liability if transmission is constrained and they do not hold corresponding transmission contracts for hours in which the spot price exceeds the strike price.

A strategic reserve offers governments an alternative insurance approach for sufficient generation capacity. It comes at the cost that during high prices generation assets in the reserve will not be dispatched unless the market no longer clears or the strike price of the strategic reserve is exceeded. While such hours are likely to be rare, it is often questioned whether the regulator might not be under pressure to allow for the early use of the generation capacity contracted for the reserve, thus moderating power price spikes but also threatening anticipated up-side benefits for generation investment. However, the limited cases of implemented strategic reserves so far have not provided 
any evidence on such behavior. European institutions could offer an additional commitment device for the dispatch rules of a strategic reserve.

Finally, whereas comprehensive capacity mechanisms may offer opportunities for national policy makers to address specific needs and provide insurance towards generation adequacy, they can come at a significant cost at the European level, in particular if they risk reducing the value of energy and flexibility provided to neighboring countries and thus the incentives for unlocking the synergies of the European system. Hence, it seems warranted to prioritize the multiple measures to strengthen the (re-)investment framework for conventional assets and flexibility, and if desired to use a strategic reserve with limited coordination requirements as insurance policy.

\section{Long-term: Continued role for remuneration mechanisms for wind and PV?}

\subsection{Cost development}

Renewable energy technologies have achieved large-scale price reductions, creating the basis for their large-scale application while at the same time contributing to EU climate objectives. This is also reflected in a contribution of at least $60 \%$ to power generation in all decarbonization scenarios of the EU Energy Roadmap 2050, and other roadmaps presenting very similar results (e.g. ECF, 2010; IEA, 2012).

Figure 6: Comparison of European fossil fuel bill and capital costs for renewables (at purchasing prices in each year) ${ }^{20}$

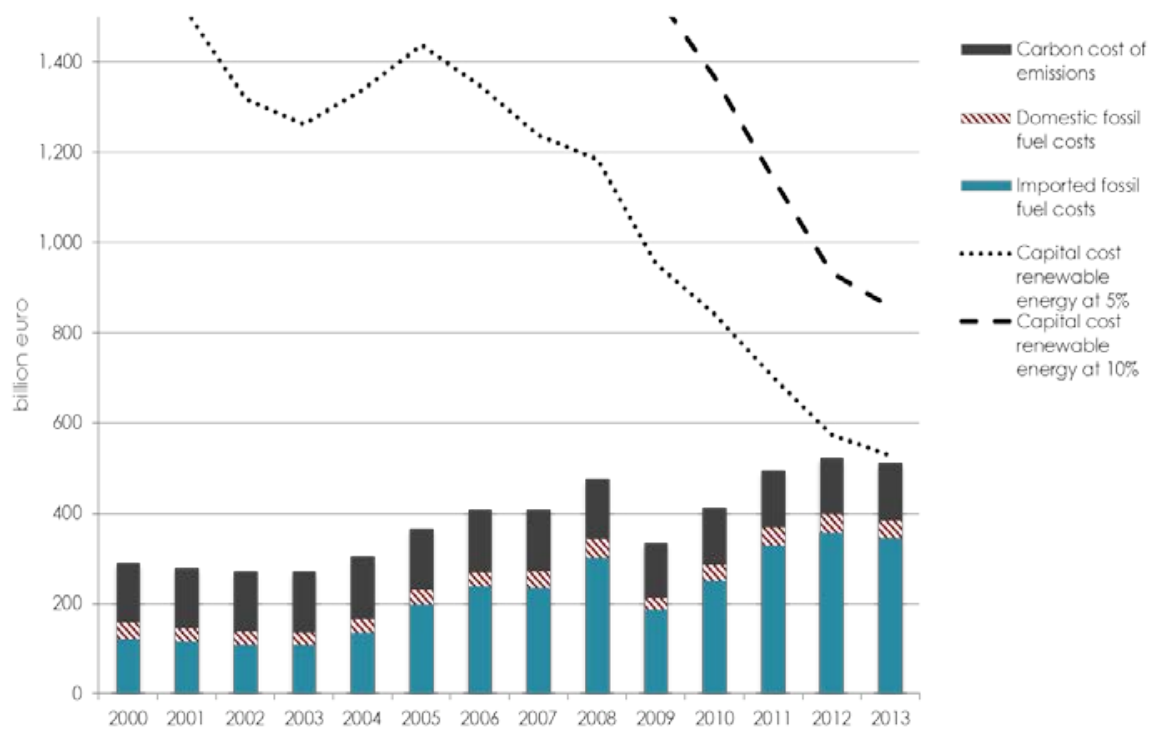

Gimate Strotegies $X$ OIW BERIII

\footnotetext{
${ }^{20}$ Calculations are based on the following simplifying assumptions: Carbon cost of $€ 30$ per ton and a nominal interest rate of $5 \%, 2 \%$ inflation, $50 \%$ fossil fuel conversion loss, $66 \%$ of energy from onshore wind and $33 \%$ from solar PV. Neither operation \& maintenance costs, nor costs of market flexibility, additional grids or energy storage are considered.
} 
The economic viability of this perspective is illustrated in Figure 6 with a very simplified example that puts aside current energy mix discussions and national politics. Assume all fossil fuel use in the EU was substituted with renewable energy. In 2013, the annualized investment cost in wind turbines and solar panels to deliver the same final energy would have been of the same size as the fossil fuel bill. This assumes that the renewable generation mix consists of onshore wind power (two-thirds) and PV (one-third), and that the final energy demand in all areas of use - including the transport sector - can be fully served with electricity.

The comparison is only illustrative and of course very simplified. In a comprehensive system analysis, further aspects have to be considered. All energy transition strategies envisage a strong emphasis on energy efficiency to reduce energy demand as compared to the business-as-usual development. This would not only reduce energy bills and $\mathrm{CO}_{2}$ emissions, but also investment costs. Moreover, besides onshore wind power and solar PV, several other low-carbon technologies complement the optimal portfolio supporting the transition to a decarbonized economy. In addition, the costs of energy storage devices, market flexibility, and additional grids, that become relevant in the case of high shares of fluctuating renewable generation, cannot be neglected, and for the evaluation of an energy system focused on RES and energy efficiency, the opportunities to save on future infrastructure investment for fossil fuels also need to be taken into account.

\subsection{Effective investment framework for intermittent RES}

As discussed in Section 3, there is both a larger need and bigger capacity for governments to guide choices regarding investments in renewable energy technologies. Their effective integration into the power system requires complementing policies on grid expansion, storage and flexibility options and spatial planning and permitting. Thus, a government choice is already immanent. Given the transparency of technology costs linked to both global technology markets and the competitive environment of multiple project developers, government can also draw on a good information base for these choices.

This can be taken into consideration in the design of the investment framework, in particular with respect to minimizing the exposure to regulatory risk and facilitating long-term hedging between consumers and generators. The importance of such choices is illustrated in the example above. The level of financing costs will be critical for the economic viability of a transition to a low-carbon economy. If the interest rate is $10 \%$ instead of $5 \%$, for instance due to political or regulatory risks, the costs of renewable energy would, in this calculation, not be in the order of magnitude of fossil fuel expenditures. At the same time, credible and stable conditions for investors are key to limit financing costs (see e.g. De Jager and Rathmann, 2008). This could argue for the continued use of remuneration mechanisms able (i) to compensate for insufficient carbon prices delivered by the EU ETS and to reflect public benefits of reducing fossil fuel import dependency; (ii) to reduce regulatory risks and manage market risks so as to facilitate access to low-cost finance; and (iii) to accelerate the investment pace towards a decarbonized power system beyond the natural replacement rate.

Financing costs are determined by the risk associated with the investment: First, the secure netrevenue determines the share of debt that can be used to finance a project and to reduce financing costs due to the lower return requirements for debt than for equity (see also Tisdale et al., 2014). Second, complexity of the regulatory framework and financial structure necessary for the implementation of a project can increase transaction costs and reduce the level of competition because fewer actors will have the capacity to engage and fewer actors will be prepared to endure 
the costs of making offers for a complex financing structure, which in turn reduces competition among finance providers and increases the cost of finance.

The experience with renewable remuneration mechanisms illustrates these points. Figure 7 compares the situation for two traditional and widely deployed support mechanisms - fixed feed-in tariffs and renewable quota systems. Countries which have deployed renewable quota systems typically offered higher remuneration levels, but yet achieved less deployment. This effect was often attributed to the need of project developers to sign long-term off-take contracts so as to provide sufficient revenue certainty to access finance. The only available counterparties for such contracts are incumbent utilities. Given the limited number of incumbent utilities, however, project developers are exposed to their market power. As the volume of renewable investment increased, the long-term (10 to 20 year) off-take contracts constituted an increasing risk exposure for incumbent utilities, thus motivating higher margins and ultimately limiting the total capacity to sign such contracts.

Figure 7: Investment profit ranges and policy effectiveness of different renewable remuneration mechanisms for onshore wind in 2009

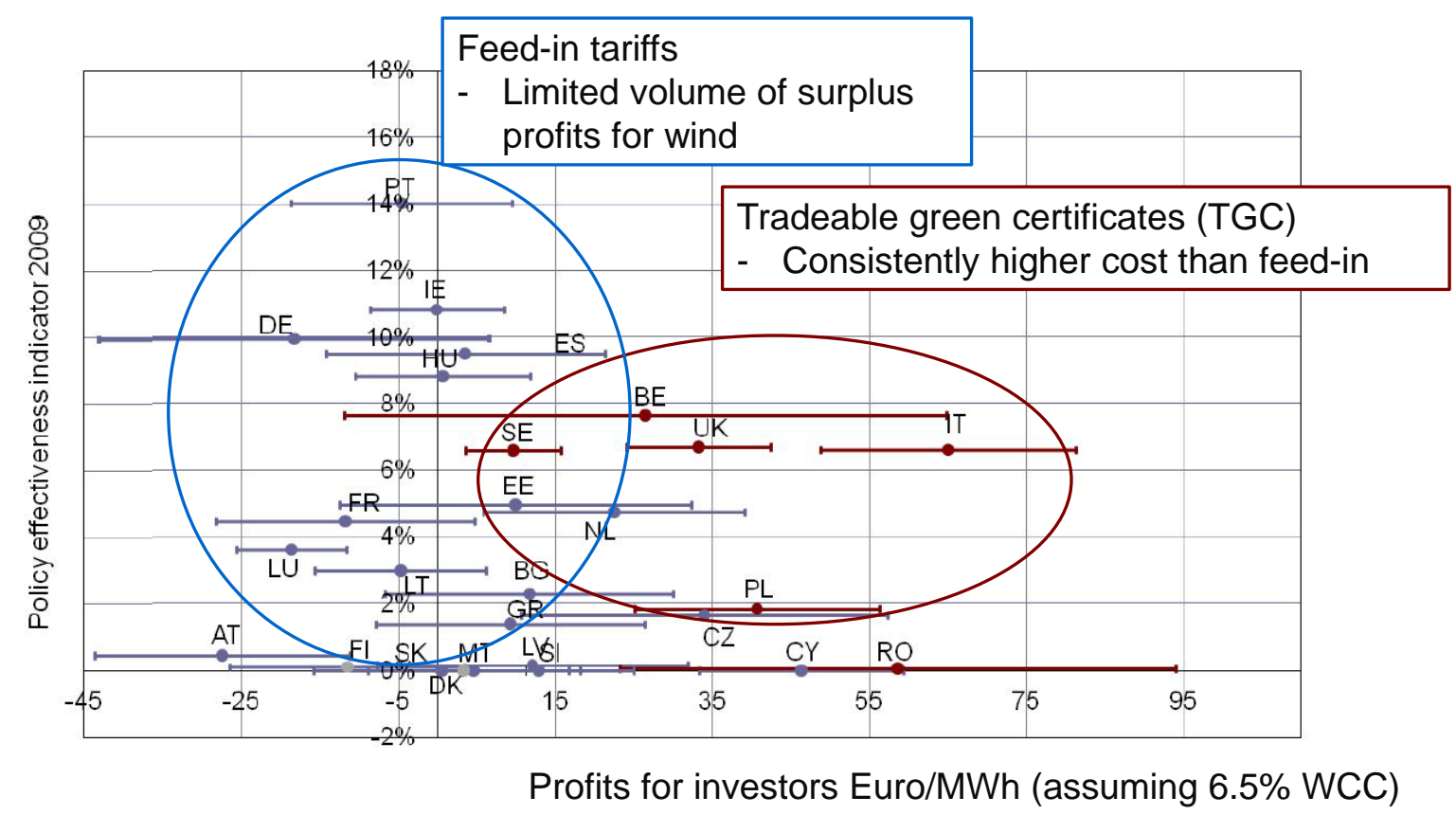

Source: EU Intelligent energy project RE-Shaping (http://www.reshaping-res-policy.eu/)

Note: For each of the European countries, the $\mathrm{x}$-axis depicts the profit level per MWh of wind electricity generated that would have been achieved based on the support mechanism in the respective country for a project developer with weighted cost of finance of $6.5 \%$. The $y$-axis depicts the percentage of the resource potential that was projected for 2020 captured per year.

In principle, generators and consumers would like long-term contracts, which allow generators to avoid low- and consumers to avoid high wholesale prices. Such long-term contracts would reduce financing costs for investors and thus at the same time also lower electricity costs and prices (Rathmann et al., 2011). Consumers would in particular like to hedge the cost of their uncertain future demand, and renewable generators would like to hedge their uncertain future output, neither of which are likely to exactly match. However, due to counterparty risks, mobility of households and 
firms, as well as EU guidelines, contracts of the necessary type and duration are unlikely to evolve without regulatory backing.

Fixed feed-in tariffs are an effective hedge against volatile prices. The difference between the remuneration level and the wholesale price level (be it positive or negative) is passed on to consumers and, thus, the instrument comprises a component of the hedging portfolio of consumers, too, hedging their exposure to spot prices for the share of power that is provided through the feed-in tariff.

With a shift from feed-in tariff to market premium systems, some of these benefits are lost. A fixed premium exposes the developer to the full market risk which can at best only be hedged forward for a few years - a short time when compared to the desirable length of any debt issued. Investors have to find private counterparties for their energy output to provide for stable enough revenue streams. As already mentioned above, in practice, only incumbent utilities have been buying renewable energy on such contracts, arguably at unfavorable terms reflecting the risk and their monopoly position. As these incumbent utilities would struggle to sign long-term contracts at the volume required to meet EU renewable targets, as this would create large risk exposure to future power prices, fixed premiums are likely to perform even worse in the future.

This motivated the development of sliding premium systems. A sliding premium pays to generation the difference between the envisaged remuneration level and an average wholesale power price. While a plausible theoretical concept, sliding premiums raise a set of questions about the future remuneration level to be expected that could significantly impact access to finance and increase financing costs: Does the computation of the reference price match the generation profile and timing of energy sales; how will evolving intraday market design impact revenues and costs related to balancing and system services; and how will the system evolve if new pricing zones are introduced?

With respect to quota systems, evidence on past experiences shows that countries which have deployed quota systems had to provide higher remuneration levels than countries which implemented feed-in tariff schemes, but despite these higher remuneration levels usually achieved less deployment (see e.g. Ragwitz et al., 2012).

The further development of the EU ETS will determine whether remuneration mechanisms can develop into effective risk hedging instruments, or whether - in the absence of a robust carbon price - renewable remuneration mechanisms will retain a support component reflecting a shadow price of carbon. The large-scale deployment of renewable energy will only be cost-competitive against coalfired power generation if the last bears an adequate carbon price. This leaves in principle three options: (1) Strengthening the EU ETS so as to re-establish a carbon price which is in line with environmental concerns. In this case, renewable remuneration mechanisms will increasingly constitute a long-term contractual guarantee to facilitate financing for producers and to stabilize electricity costs for consumers; (2) alternative regulatory instruments limiting the capacity and operational hours available to them. This approach effectively creates a shadow price on coal-fired generation; ${ }^{21}$ or (3) significant support elements remaining part of RES remuneration mechanisms to compensate for the lacking carbon price. The development of the last two years demonstrates that this approach is in principle possible, but faces the political difficulty of communicating the scale of

\footnotetext{
${ }^{21}$ However, the approach will likely limit the flexibility of operating coal-fired units at a time when we have limited visibility on their effective use, i.e. during a gas crisis, or, as these units are generation assets of last resort, for example for the infamous cold winter week with very low wind.
} 
the renewable surcharge and on distributing it especially to electricity-intensive industrial consumers facing inter-European and international competition. In principle, it would be possible to deploy increasing shares of RES in any one of these three scenarios. However, the credibility of the overall policy framework for the supply chain, project developers, investors and utilities will differ according to the development trajectory.

Moreover, avoiding distortions of short-term markets is an important design criterion for any renewable remuneration mechanism. Feed-in systems are often criticized for negative prices in spot markets. It is, however, the priority dispatch rule that contributes to negative prices. This rule has been formulated to avoid discrimination against RES technologies by incumbents and to ensure that investors do not face undue delays in commissioning projects where institutions and regulation have not been adapted to the needs of renewables. With increasing RES shares in the power system, the priority dispatch rule results in hours of negative prices if inflexible generators (including not only wind and solar, but also conventional resources) continue to be dispatched. Accordingly, the stringency of this rule has been gradually reduced across Europe. ${ }^{22}$

Where short-term markets are inefficiently structured and distorted through strategic actions, there is rational for encouraging private actors to use clever sales strategies for renewable energy, rather than requiring a regulated and thus inflexible public entity to resell the power originating from a feed-in system. But the world of wholesale power markets and wind forecasting is quickly evolving and, with increasing liquidity and increasing use of auction platforms at day-ahead and intraday stage (see Section 2), both public and private actors can buy the same wind forecasts, submit the same bid to sell power, and will receive the same revenue from selling the power. The requirement for all wind generators to balance their positions and employ agents to contract to sell the power is arguably a barrier to entry for new developers and a protection for incumbent utilities, from whom the new entrants are effectively forced to buy these services, often at a heavy discount. Good power market design is ultimately the key for good market outcomes - irrespective of the design of the RES remuneration mechanism.

\section{Summary and conclusions}

In today's EU power market, intermittent low-carbon generation and dispatchable fossil-fuel based generation complement each other. The two technology groups are fundamentally different, concerning not only the relevance of upfront investment costs, but also investors' main strategic choices and the capacity of governments to take a stronger part in those decisions. We have discussed how these differences between technology groups could be reflected in one potential power market design in a consistent manner. Other approaches might be possible, and should then be compared against the overall package to guide a longer-term strategy that makes full use of the value provided by renewable and conventional generation and that provides at the same time a framework to guide investment, re-investment and closure decisions and to unlock various flexibility resources.

\footnotetext{
${ }^{22}$ A feed-in tariff can allow for wind or solar spill at negative prices, and can compensate investors for the energy that is spilled once priority dispatch is no longer needed.

In this vein, the new State Aid Guidelines ( $\operatorname{COM}(2014) 2322)$ also require that premiums are only paid at times when the wholesale price is not negative, but so far questions remain about the implementation of such a rule and its impact on finance still needs to be explored.
} 
First, for operational choices in the short-term, we cannot consider different markets for the different generation technologies, but instead an adequate market design needs to recognize the complementary, though different nature of renewable and conventional assets. Short-term power markets with large shares of intermittent RES need some revision - amongst others, guaranteeing system security in an efficient manner involves a pooling of resources over larger geographic areas; complex bids could resolve the perceived conflict between increasing temporal granularity of products, while at the same time respecting technical plant capacity in the bidding structure; and flow-based transmission allocation and smaller pricing zones can enhance efficiency in the use of transmission capacity. The Target Model so far leaves TSO operation as a kind of black box risking secure system operation and efficient cooperation. It remains open whether common market protocols suffice to ensure secure and efficient operation of the European power system in the longer-term. Operational approaches of TSOs might diverge rather than converge. We may thus wonder if for the post-2014 period further refinements of market protocols and some regulatory guidance for TSOs in order to avoid increasing divergence in processes are needed.

Second, debates on the financial viability of existing conventional assets as well as on the capacity to finance new conventional plants are ongoing. Equally important is the appropriate remuneration for flexibility options within the power sector and at the interface to heat, industry and transport sectors. However, current surplus generation capacity in several European countries has resulted in low margins and flat price profiles, motivating companies to mothball or decommission plants and providing little incentive for demand side options. This raises the question on the appropriate policy response to maintaining generation adequacy with a generation mix that is compatible with security of supply and environmental and flexibility requirements of the evolving power system. Forward contracting can provide a mean of hedging fuel costs and stabilizing revenue streams. It allows to hedge against high price volatility, and also to protect consumers against high-price periods.

Third, as the economics of wind and solar PV projects are dominated by up-front investment costs, stable enough revenue streams are required for large-scale renewable projects for a longer-term horizon in order to allow for investments by risk-averse actors that can provide capital at low cost and thus support the economic viability of a transition to a low-carbon economy. There are tangible benefits of a differentiated treatment of wind- and solar PV investments as compared to conventional fossil fuel based generation assets, linked to capital cost and governance. This suggests a continued role for renewable remuneration mechanism. They can play an additional role by facilitating an accelerated transition to a decarbonized economy.

While each of these aspects is often discussed individually, the paper aims to contribute to the debate by demonstrating that a policy framework for efficient short-term operation of the overall system is compatible with a differentiated investment framework that addresses the needs of different groups of generation technologies. In particular, an efficient market design that reflects physical realities can provide a suitable reference point for the design of flexibility products and financial contracts to support innovation and investment in flexibility options and conventional generation technologies. At the same time efficient and liquid short-term markets facilitate the provision of flexibility and energy by all technologies and actors. As such they also can accommodate for different regulatory structures for investments in different groups of generation technologies. 


\section{References}

ACER (2013): Capacity remuneration mechanisms and the internal market for electricity. ACER Report.

ACER/CEER (2012): Annual market report. ACER/CEER Report.

Aïd, R., G. Chemla, A. Porchet and N. Touzi (2011): Hedging and vertical integration in electricity markets. Management Science, 57(8): 1438-52.

Bertsch, J., C. Growitsch, S. Lorenczik and S. Nagl (2015): Flexibility in Europe's power sector - An additional requirement or an automatic complement? Energy Economics, in press.

Bessembinder, H. (1991): Forward contracts and firm value: Investment incentive and contracting effects. Journal of Financial and quantitative Analysis, 26(4): 519-32.

Breuer, C. and A. Moser (2014): Optimized bidding area delimitations and their impact on electricity markets and congestion management. Conference Paper, European Energy Market (EEM) 2014.

Burstedde, B. (2012): From nodal to zonal pricing - a bottom-up approach to the second best. Conference Paper, European Energy Market (EEM) 2012.

Chaves-Ávila, J.P. and C. Fernandes (2015): The Spanish intraday market design: A successful solution to balance renewable generation? Renewable Energy, 74: 422-32.

Cramton, P., A. Ockenfels and S. Stoft (2013): Capacity market fundamentals, Economics of Energy \& Environmental Policy, 2(2), 27-46.

De Jager, D. and M. Rathmann (2008): Policy instrument design to reduce financing costs in renewable energy technology projects. Ecofys Report.

ECF/McKinsey (2010): A practical guide to a prosperous low-carbon Europe.

Ecofys (2014): Flexibility options in electricity systems.

ENTSO-E (2014): Scenario outlook and adequacy forecast 2014-2030. Online: https://www.entsoe.eu/publications/system-development-reports/adequacyforecasts/Pages/default.aspx

Erlinghagen S. and J. Markard (2012): Smart grids and the transformation of the electricity sector: ICT firms as potential catalysts for sectoral change. Energy Policy, 51: 895-906.

Eurelectric (2010): Eurelectric response to Commission request for clarification. Online: http://www.google.de/url?sa=t\&rct=j\&q=\&esrc=s\&source=web\&cd=3\&cad=rja\&uact $=8 \& v e d=0 C$ DsQFjAC\&url=http\%3A\%2F\%2Fwww.eurelectric.org\%2Fmedia\%2F43933\%2Feurelectric respons e to commisison request for clarification-2010-030-0109-01e.pdf\&ei=Qx SVP3al4L4ygOMw4LYBQ\&usg=AFQjCNE8JmTWq7wNikrUBrGxhHcDEzDMbQ\&sig2= YQvdo1-4dFpJzWnDpkr6bA

European Commission (2009): Directive concerning common rules for the internal market in electricity. Directive 2009/72/EC.

European Commission (2014): Communication from the Commission on 'Guidelines on State aid for environmental protection and energy 2014-2020'. C(2014) 2322.

EU (2012): Consultation Paper on Generation Adequacy, Capacity Mechanisms and the Internal Market in Electricity.

EWI (2012): Flexibility options in European electricity markets in high RES-E scenarios. Study on behalf of the IEA.

Glachant, J.-M. and S. Ruester (2014): The EU Internal Electricity Market: Done forever? Utilities Policy, 30: 1-7. 
Hogan, W.W. (2012): Electricity scarcity pricing through operating reserves: An ERCOT window of opportunity. Online: http://www.hks.harvard.edu/fs/whogan

IEA (2012): Energy technology perspectives 2012 - Pathways to a clean energy system.

Imran, K. and I. Kockar (2014): A technical comparison of wholesale electricity markets in North America and Europe. Electric Power Systems Research, 108: 59-67.

Leprich, U., D. Bauknecht, K. Schrader, S. Peter, and H. Bokelmann (2008): Optimierungsstrategien aktiver Netzbetreiber. BMU Studie.

Neuhoff, K. and L. De Vries (2004): Insufficient incentives for investment in electricity generations. Utilities Policy, 12(4): 253-67.

Neuhoff, K. and D. Newbery (2005): Evolution of electricity markets - Does sequencing matter? Utilities Policy, 13(2): 163-73.

Neuhoff, K., Hobbs, B.F. and Newbery, D. (2011): Congestion management in European power networks - Criteria to assess the available options. DIW Berlin Discussion Paper 1161.

Neuhoff, K., J. Diekmann, W.-P. Schill and S. Schwenen (2013): Strategische Reserve zur Absicherung des Strommarkts. DIW Berlin Wochenbericht 48/2013.

Pollitt, M. (2012): The role of policy in energy transitions: Lessons from the energy liberalisation era. Energy Policy, 50: 128-37.

Ragwitz, M. et al. (2012). RE-Shaping: Shaping an effective and efficient European renewable energy market. Final Report of the Intelligent Energy Europe project Re-Shaping.

Rathmann, M., De Jager, D., De Lovinfosse, I., Breitschopf, B., Burgers, J., Weöres, B. (2011): Towards triple-A policies: More renewable energy at lower cost. Re-Shaping D16 Report.

RE-Shaping (2011): Indicators assessing the performance of renewable energy support policies in 27 Member States. D17 Project Report.

Ruester, S., X. He and J. Vasconcelos (2013): Electricity storage - Need for a particular EU policy to facilitate its deployment? European Energy Journal, 3(2): 23-31.

Ruester, S. and S. Schwenen (2014): Europäische Perspektive für Versorgungssicherheit auf Strommärkten notwendig. DIW Roundup 14/10/2014.

Ruester, S., S. Schwenen, I.-J. Perez-Arriaga and C. Batlle (2014): From distribution networks to smart distribution systems: Rethinking the regulation of European electricity DSOs. Utilities Policy, 31: 229-237.

Schill, W.-P. (2014): Residual load, renewable surplus generation and storage requirements in Germany. Energy Policy, 73: 65-79.

Schill, W.-P. and C. Kemfert (2011): Modeling Strategic Electricity Storage: The Case of Pumped Hydro Storage in Germany. The Energy Journal, 32(3): 59-87.

Schleiche-Tappeser, R. (2012): How renewables will change electricity markets in the next five years. Energy Policy, 48: 64-75.

Schröder, A., F. Kunz, J. Meiss, R. Mendelevitch and C.v. Hirschhausen (2013): Current and prospective costs for electricity generation until 2050. Data Documentation 68, DIW Berlin.

Sikorski, T. (2011): Redesign of Polish electricity market and its integration into single European market. Presentation at the $6^{\text {th }}$ Market Design Conference, Stockholm, October 2011.

Süßenbach, W., M. Schwaiger and H. Stigler (2011): Kapazitätsmärkte und Mechanismen im internationalen Vergleich, Internationale Energiewirtschaftstagung an der TU Wien. 
Tisdale, M., T. Grau and K. Neuhoff (2014): Impact of Renewable Energy Act reform on wind project finance. DIW Berlin Discussion Paper 1387.

VDE (2012): Erneuerbare Energie braucht flexible Kraftwerke - Szenarien bis 2020. Studie der Energietechnischen Gesellschaft im VDE (ETG). 